\title{
METHOD FOR ASSESSING THE NATIONAL IMPLICATIONS OF ENVIRONMENTAL IMPACTS FROM TIMBER BUILDINGS-AN EXEMPLARY STUDY FOR RESIDENTIAL BUILDINGS IN GERMANY
}

\author{
Annette Hafner* \\ Professor for Resource Efficient Building \\ Department of Civic and Environmental Engineering \\ Ruhr-University Bochum \\ Universitätsstraße 150 IC 5-159, 44801 Bochum, Germany \\ E-mail: annette.hafner@rub.de
}

Sebastian Rüter

Head of Unit Impact of Wood Utilisation on Environment and Climate

Thünen Institute of Wood Research

Leuschnerstraße 91c, 21031 Hamburg, Germany

E-mail: sebastian.rueter@thuenen.de

(Received October 2017)

\begin{abstract}
Since 2012, a set of new standards describing, among other aspects, the use of life cycle assessment (LCA) in the construction sector is available in Europe and provides a framework for consistently assessing the environmental performance of buildings. This article gives an overview of the actual state of art for evaluating the environmental properties of timber buildings in Europe and shows how these methods could be used as a basis for estimating the influence of a possible shift from conventional buildings to timber buildings on the national "Greenhouse Gas (GHG) budget," whereby Germany serves as an example. Results from up-to-date LCA calculations of residential buildings for Germany are shown on a building level. Then a scaling from the building level to a national level is presented. On the national scale, the potential GHG impact of wood consumption in the building sector is modeled based on an insinuated future increase of the market share of timber buildings. The deviation of future emissions and removals due to the biogenic carbon storage effects for changing scenarios is presented. The approach shows how increasing timber construction (mass timber and timber frame) can contribute to achieving climate protection targets.
\end{abstract}

Keywords: GHG, LCA, carbon storage, timber buildings, mass timber, CLT.

\section{INTRODUCTION}

\section{General}

In accordance with the agreement of the 2015 Paris Climate Change Conference (UNFCCC 2017) and in pursuance of sustainable development goals, Europe has defined ambitious climate protection goals to be reached by 2050 . In this context, the building sector was identified as a major player for reducing greenhouse gas (GHG) emissions in Europe (EC 2014), which requires the involvement of all subsectors, from industry and infrastructure to buildings and cities. Optimizing the environmental impact during

\footnotetext{
* Corresponding author
}

a building's life cycle is, therefore, a significant aim in the context of attaining the desired sustainable development. Timber as building material can play a vital role in reducing global warming potential (GWP) in the context of reaching climate protection targets in the building sector (Hafner 2017). As trees grow, they absorb carbon dioxide from the atmosphere and temporarily store it in the wood as carbon. Therefore, all renewable materials function as temporary carbon storage in the building life cycle. The more renewable material masses installed in a building, the higher the carbon storage is. But, it is necessary that all timber used in the building sector be sourced from sustainable forestry practices.

Although past discussions on the potential contribution of the building sector to climate change 
mitigation concentrated on the aspect of energy efficiency during the building's operational use phase, a broader focus now takes other environmental aspects into consideration, and thus includes the climate relevant performance of building materials used in construction. Having largely achieved increased energy efficiency during the use phase through Energy Performance of Buildings Directive (nearly zero energy buildings, EC 2010), both the impact of the primary energy consumption for the manufacturing of products and the reduction of GHG emissions over the entire life cycle of buildings steadily gained importance.

In national GHG accounting there are currently four effects of carbon capturing accounted for, carbon pool of forest, carbon pool of products, material substitution, and energetic substitution. The first two are accounted for in the national inventory report and declared to the climate secretary of the UN. The substitutions are avoided emissions, which are not directly accounted for in the sector but may help to reduce emissions from other sectors (Heuer et al 2016) when sustainable forestry can be presumed.

Although the inclusion of substitution and temporary carbon storage capacity on the achievement of the climate protection goals can only be applied to the entire national-wide sector, it can be demonstrated on a building level.

\section{Standards on Life Cycle Assessment (LCA)}

In this context, the method of LCA allows for calculating and presenting a number of climate impacts of buildings during their life cycle. For both to increase transparency in the provision of such environmental information in the construction sector and, last but not least, to prevent trade barriers due to inconsistent systems in Europe, the technical committee CEN/TC 350 "sustainable construction works" of the European Committee of Standardization was set up in 2005. It was responsible for the development of a series of horizontal standards regarding this set of issues (Rüter 2012). These LCA related standards are the same as the basic concepts in the whole of Europe.
In 2012, a set of new standards describing the use of LCA in the construction sector, among other aspects, was made available in Europe, providing a framework for consistently assessing the environmental performance of buildings. The standards include EN 15643 (2010), which provides the general framework; EN 15978 (2012), which provides calculation rules on a building level; and EN 15804 (2014), which offers rules on how to calculate on a building product level. As one of the essential results of the European standardization process, the standards now provide clear rules for the preparation of LCA that reflect the entire life cycle of buildings and their construction products within a modular approach. This comprises the production phase (module A); the use phase (module B); and includes both guidance on the handling of end-of-life (EOL) impacts in module $\mathrm{C}$ and the treatment of recycling potentials in module $\mathrm{D}$. In particular, the standards require separating the calculated impacts represented in modules $\mathrm{C}$ and $\mathrm{D}$, which, before this regulation, were most often summed up as one value, leading to inconsistent and opaque LCA results.

The new standards also have consequences for the findings in many available LCA studies, which focus on comparing the material use of wood especially in the building sector with alternative building materials (cf. Sathre and O'Connor 2010). Most of the studies before the new set of calculation standards concluded that the production of wood-based materials resulted in reduced GHG emissions and that wooden building products were also associated with lower emissions over their entire life cycle (Sathre and O'Connor 2010).

Despite the issuance of horizontal standards for sustainable construction methods, it became obvious that further guidance was needed regarding aspects especially relevant to wood, as both an organic and renewable building material.

The material use of wood extends the storage period of biogenic carbon sequestered by trees from atmospheric $\mathrm{CO}_{2}$, thus, delaying the release of these emissions into the atmosphere. In fact, the 
carbon transferred from living biomass into the product system during the timber harvest and its subsequent processing leaves the product system again at its EOL, which results in a zero-sum game over the product's entire life cycle (cf. Rüter 2013).

\section{National GHG Reporting}

On the national level, however, changing patterns of wood consumption (eg more timber buildings) can result in a significant sink or source effects of biogenic $\mathrm{CO}_{2}$ emissions. Since 2013, the associated effects are presented as contribution to the land-use sector's GHG emissions by sources and removals by sinks under the Kyoto Protocol and the United Nations Climate Change Convention (UNFCCC) in the national GHG inventory reports (UNFCCC 2012; Rüter et al 2014; Rüter 2016). Their reports are annually published by each party to the Kyoto Protocol and Annex-I member states. Under the Kyoto Protocol, the estimates are conducted for wood originating from domestic forests being consumed domestically and for exports. Since 2013 the carbon storage effect in wood products is included in the national accounts of the signing parties to the Kyoto Protocol. Since then, temporary and dynamic changes in the carbon pool of harvested and used wood must be considered. Exactly for these considerations, comparative LCA on a building level based on agreed methodology is essential. The decision to include the carbon storage effects of the material use of timber in wood products in the national GHG inventory reports was also motivated by the intention to better reflect the temporal dynamics of forest sector emissions and to enable the consideration of positive substitution effects associated with the use of wooden material in national climate policies (cf. Rüter 2012, 2017). However, to assess the environmental and GHG-relevant impact of wood consumption within the national building sector consistently with these annual reports of the biogenic carbon storage effects, the application of the standard-compliant LCA information on the building level is essential.

To adequately depict the storage effect of biogenic carbon on the product level and to enable a correct calculation of GHG emission budgets associated with the use of wood as energy carrier at its EOL, following the issuance of European standard EN 15804, the European standard (EN 16485 2014) was developed. This standard is also compliant to the international standard ISO 21930 which specifies the calculation rules for assessing the sustainability of building products (ISO 21930 2017). It includes further clarifications, especially on the treatment of biogenic carbon in wood and wood-based products used in the construction sector.

The aim of this article is to set out a consistent method for assessing the environmental and GHG impact of timber buildings on a national level. The article, therefore, provides an overview of the actual state of art methodology for conducting LCA of buildings and shows how these methods can be applied for estimating the implications of a possible shift from conventional buildings to timber buildings for the national GHG budget, using Germany as an example.

\section{MATERIALS AND METHODS}

\section{Standards on Environmental Issues in the Building Sector in Europe}

The building-level standard (EN 15978 2012) and the product-level standard (EN 15804 2014) are based on the same classification of relevant life cycle stages (shown in Fig 1). Within the applied system boundary for the building assessment, this includes the modules A (product stage), B (use stage), and C (end-of-life stage). As the additional Module D (benefits and loads beyond the system boundary) is noted as supplementary information beyond the building life cycle, it is shown separately as required by the standard.

Modules A1-A3 cover the "cradle to gate" processes for the materials and services used in the construction. This includes the extraction and processing of raw material and the processing of secondary material input (A1), transport of the materials to the factory gate and internal transports (A2), and the production of ancillary materials or preproducts, products, and coproducts 


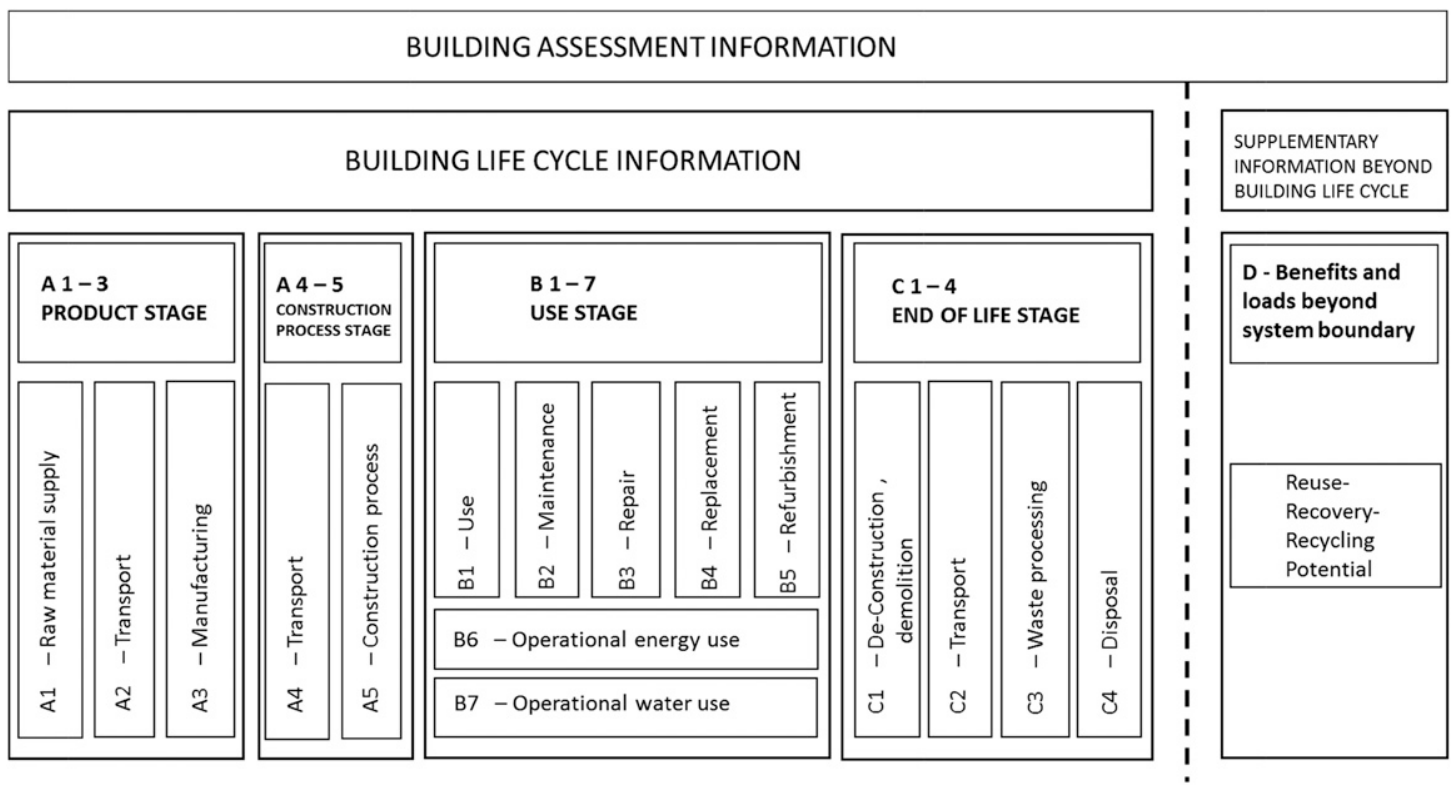

Figure 1. Modular information for the different stages in life cycle assessment according to EN 15978 and EN 15804. Modules A-C represent the life cycle, module D is calculated separately.

(A3) (EN 15804 2014). Module A4 and A5 are in most cases not yet included because of a lack of data for many products and services. Following EN 16485 (2014), the photosynthesis and the associated growth of the trees serving as feedstock for wood products are, thus, outside the product's system boundary. On harvest and during the subsequent processing of the timber into the specific wood product, the biogenic carbon contained in the living biomass is transferred to the product system.

Module B2 (maintenance) and B4 (replacement) cover all actions during the service life associated with the return of a construction product to a condition in which it can perform to its required functional or technical performance, by maintaining or replacing an entire construction element. In Germany, the number of replacements for a component is based on the table "Service life of building elements," published by the Federal Institute for Research on Building, Urban Affairs and Spatial Development (BBSR) (BMUB 2011). The component replacement includes both the production and the EOL processes, and ancillary materials used for replacement.
The Module B2 includes cleaning, planned servicing, and maintaining an installed product. Because there are no LCA data provided for cleaning products nor fresh water (B7) or sewage, the cleaning component of this module is not considered up-to-date in the LCA. Planned servicing in terms of applying protective coatings takes place in regular cycles according to the aforementioned table (BMUB 2011). B6 sums up all energy use in the life cycle of the building.

Module $\mathrm{C}$ accounts for the waste processing for reuse, recovery and/or recycling (C3), and disposal (C4). It is assumed that the recyclability of all materials is a given and that materials are sorted according to the prevailing recovery regulations. The basis for calculating the EOL phase is today's state of the art disposal engineering (EN 15804 2014).

Module D allows for including supplementary information beyond the building life cycle and outside the system boundary. It contains calculated benefits and environmental loads resulting from the recycling of materials, reuse of products (material substitution), and recovery of energy (energetic substitution). In module D, the GHG 
emissions of all building elements are summed up. The benefits and loads are calculated according to the current level of knowledge about recycling. In fact, the recycling potential can first be realized after a time span of $50 \mathrm{yr}$, when the end-of-life of the building is reached and depends as well on future means of dealing with building waste. Furthermore, it is still uncertain if the recycling potential can be completely utilized or if waste categories cannot be separated entirely.

In Germany, the Federal Ministry of the Interior, Building and Community provides an LCA database called "ÖKOBAUDAT" (Sustainable Construction Information Portal), which contains consistent datasets of a wide range of building products, fulfilling the current normative requirements of EN 15804 (BBSR 2016). The database is freely available in the web and regularly updated by the German Federal Institute for Research on Building, Urban Affairs and Spatial Developement (BBSR) (BMI 2018). Internationally, the database is well accepted as the basis for conducting building LCAs (Brockmann 2017). On the European level, efforts are presently being made to internationalize the datasets to create a consistent and coordinated way of using material- and product-relevant LCA data at the building level in Europe (Brockmann 2017).

\section{LCA of Wooden Products-Example on CLT}

For wooden building products, the Thünen Institute of Wood Research provides national average datasets ("Durchschnitt DE") in the ÖKOBAUDAT database that were compiled in cooperation with numerous enterprises of the German wood working industry and their associations. Detailed information on the applied modeling approaches and results are provided in the referenced literature (cf. Rüter and Diederichs 2012; Diederichs 2014a, 2014b; BBSR 2015). As the datasets were generated in 2012 with a validity of $5 \mathrm{yr}$, they needed to be updated in 2017, based on newly available information (including new background data, such as energy mix). Table 1, an example of such an LCA dataset, shows updated LCA results of the wooden building product cross-laminated timber (CLT), as prepared in line with EN 15804 (2014) and as included in the updated database version ÖKOBAUDAT 2017 (BMI 2018).

Standard-compliant LCA datasets for building products form the basis for evaluating the environmental impacts of buildings across their entire life cycle and for comparing different building types.

\section{Comparative LCA of Buildings}

Substitution factors illustrate potential differences in the environmental performance of the use of different building products. They are to be derived from calculations according to EN 15978 (2012) on the building level only. For this purpose, the LCA datasets for all materials incorporated in the assessed buildings are required to meet the requirements of EN 15804 (2014). For this study, these datasets were derived from the German database ÖKOBAUDAT for building products (see previous paragraph).

This article uses results from the research project "GHG - Timber Buildings" (Hafner et al 2017), in which substitution factors on the building level for small residential buildings and multistorey residential buildings (MSRBs) were identified based on comparative building LCAs according to the current normative standards. In addition, a calculation of the used mass of wooden material and the temporarily stored carbon for each building was performed. For details on the method for calculating the substitution factor, see Hafner and Schäfer (2017) and Hafner et al (2017). All comparative LCA datasets on the building level were verified by a critical review process in accordance with ISO/TS 14071 (2014) with an external review panel. The analyzed buildings are representative buildings for the German building stock which have been built according to state of the art construction methods. Each individual building that was constructed in timber (some in CLT, others in timber-frame or a combination) was additionally modeled as a functionally equivalent conventional building 


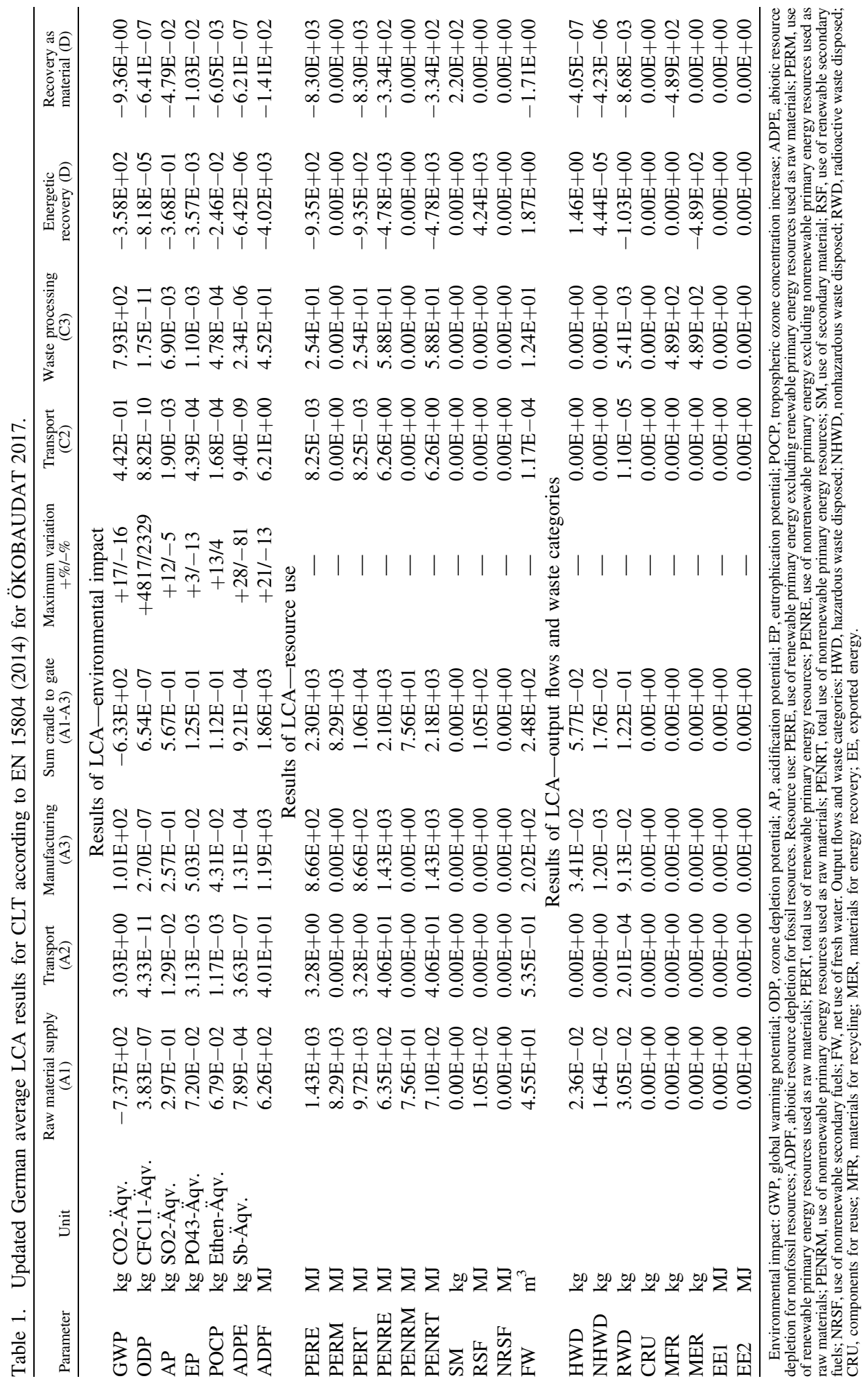


with the same qualities. In total, 25 single-family houses (SFHs)/two-family houses and 23 MSRBs with various building designs were part of the study. For detailed information on the buildings see Hafner and Schäfer (2017) and Hafner et al (2017).

Other building categories such as office buildings, schools, factory buildings, agricultural buildings, or renovation and extension of existing buildings have yet to be undertaken. For Germany, these building types are to be assessed in an ongoing research project HolzImBauDat (FNR 2017).

The functional equivalent for each comparative LCA ensures the fulfillment of the technical and functional requirements of the buildings. As basic functional quality, all analyzed buildings comply with the minimum requirements by law and the state of the art status. This means that all buildings in this study achieve the same requirements concerning structural safety and load carrying capacity of the construction, fire protection requirements according to the building regulations, and noise protection. All buildings comply with or surpass the requirements of the Energy Conservation Act 2009 (EnEV 2009) and, therefore, meet the structural physical prerequisites in all seasons. Furthermore, the technical equipment for heating and warm water generation are the same for the buildings that are compared with each other.

The functional equivalent is restricted to the essential requirements on the building elements and represents the minimum standard over the total life cycle of the building which has to be reached by all buildings. Because of the different construction types, there are gradual differences relating to the over-achievement of specific requirements (for example, fire protection requirements in conventional buildings can reach a higher protection level in the used construction than the timber construction, but both meet the regulations). All analyzed buildings comply with the abovementioned requirements as closely as possible. Slight differences result from thermal storage effects of the material, hydrothermal characteristics, load-bearing structure, and weights (as timber structures are lighter than conventional structures, which require adjustments to the foundation).

The functional unit is the provision of $1 \mathrm{~m}^{2}$ gross external area (GEA) of the product system "building" over a life cycle of $50 \mathrm{yr}$, with a life cycle of $50 \mathrm{yr}$ being the working assumption.

\section{Modeling the GHG Impact of Wood Consumption in the Building Sector on the National Level}

The first step taken in evaluating the potential GHG impacts of an increased share of wooden buildings was combining the life cycle inventory (LCI) data from the building level with both the national statistics on building activity and the national production and trade statistics of semifinished wood products (Rüter and Diederichs 2017). The LCI data from the comparative LCA calculations for the assessed buildings served as input data. Annual national statistics on the building completion according to the mainly used material component of the buildings were used to create a baseline for the historic data. The combination with annual production and trade statistics of semifinished wood products helped to identify all wood products allocated to the assessed building segments. Then, the deviation of the estimated GHG emission budgets of selected scenarios was determined against a defined reference scenario ("REF"), differentiating between GHG emissions associated with the manufacturing and EOL of building materials (in other words, the building life cycle impacts) and the estimates of the biogenic carbon budget.

The definition of the selected reference scenario ("REF") covering the period from 2016 to 2030 was based on the housing market forecast 2030 for Germany provided by the BBSR, which was applied in combination with current extrapolated building statistics (cf. Rüter and Diederichs 2017). According to the forecast, there is actually a large need for building activity which will continuously reduce from 2020 onward. With 
regard to historic development, the building statistics show that in the reference period used for the projection, on average (2011-2015) around $16 \%$ of all new residential buildings were timber buildings. This is shown in Fig 2 by the dark gray part. The scenario "REF" assumes continuous rates of mainly used material components for the classification of buildings erected in the future.

One of the selected scenarios assesses the GHG implications of a very optimistic development path, supposing a continuous increase in the national timber construction rate, both for SFH from its current rate of $16.2 \%$ to $55 \%$ and MSRB from $1.1 \%$ to $15 \%$ at the expense of an evenly distributed decrease of conventional buildings by the end of the scenario period in 2030 (" $55 / 15$ ", Fig 2). Figure 2 shows the historic (till 2015) and the suggested future (2016-2030) development of new buildings and the scenario-dependent share of wooden buildings.

The estimation of the national mitigation potential of the scenarios in terms of substitution potential and biogenic carbon storage effects was implemented in the computer model WoodCarbonMonitor (Rüter 2017), which is also used for the German national GHG reporting under the
UNFCCC and the Kyoto Protocol following the methodological requirements of the Intergovernmanetal Panel on Climate Change (IPCC) (Rüter et al 2014; Umweltbundesamt 2017). In contrast to the estimation approach applied for national GHG reporting, the so-called stockchange approach was used in this study to assess the impact of an increased wood consumption in the building sector. It calculates the carbon storage effect, which is subsequently used to determine $\mathrm{CO}_{2}$ emissions by sources and their removals by sinks over a defined time span on the basis of all domestically consumed wood products (Rüter 2017).

Thus, the possible carbon storage potential was determined by means of identifying the quantity of wood construction products used in the construction of defined buildings in the study "GHG-timber buildings" (excluding interior works), which were allocated according to the buildings statistics, calculating both the absolute impact on emissions and removals and the deviation of the increased wood consumption scenario ("55/15") from the "REF" scenario. Consistent with the storage effects and the potential impact on the demand for wood as a raw material, it was also possible to depict the

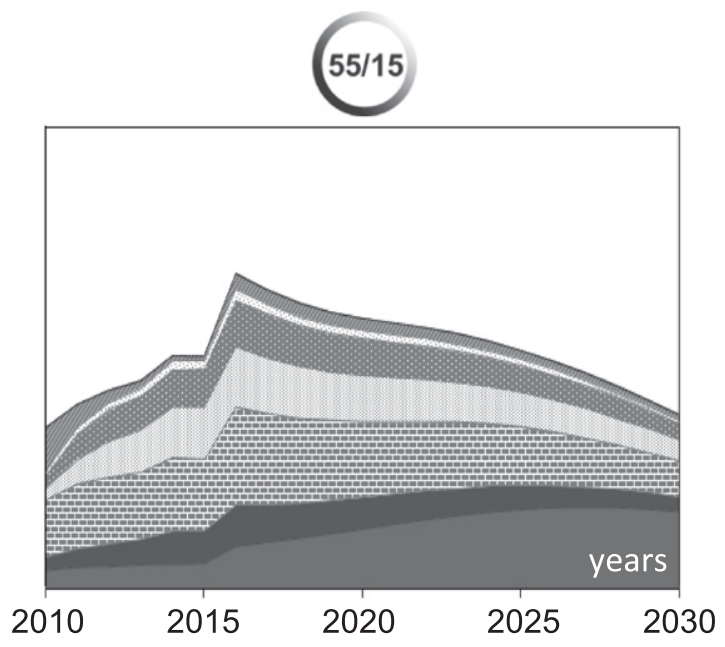

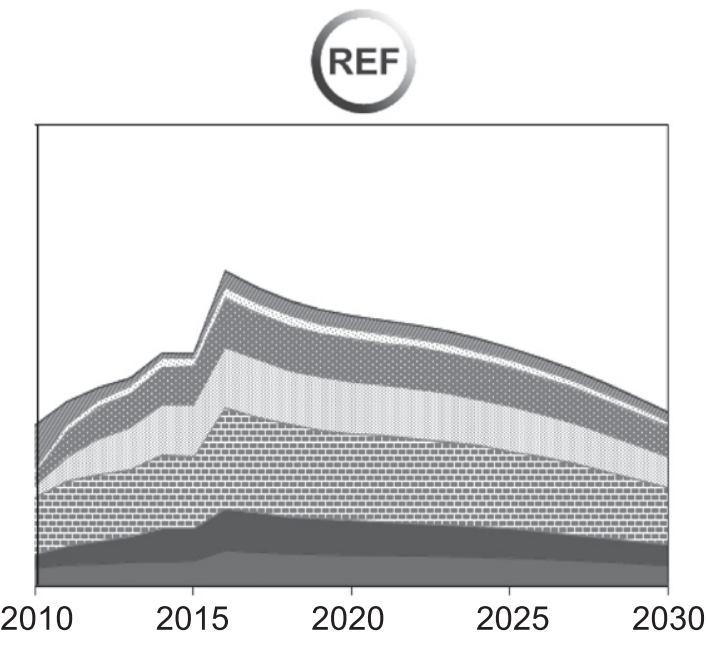

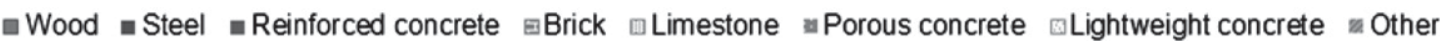

Figure 2. Schematic overview of the scenario-dependent change in the share of wooden residential buildings over the period 2010-2030 (Rüter and Diederichs 2017). 
possible substitution effects and the potential demand for timber feedstock associated with the wood consumption in the construction sector in Germany deviating from the reference case ("REF").

\section{RESULTS AND DISCUSSION}

The described results both on the building level and on the national level are part of the study "GHGtimber buildings" by the authors of the article.

\section{Comparative LCA on a Building Level}

Figure 3 illustrates the GWP per $\mathrm{m}^{2}$ GEA for the one exemplary single-family timber building (mass timber construction) and three conventional counterparts (ie porous concrete, perforated brick + insulating plaster, perforated brick + mineral wool). In addition, results are shown for one MSRB with three mineral counterparts (Fig 4). The total GWP for a building is the sum of fossil and biogenic GWP. According to EN 16485 (2014), in module A, the biogenic GWP is negative because carbon is stored in the timber building products. Because of higher wood masses in timber buildings, higher biogenic (negative) GHG emissions occur than in conventional buildings (see Fig 3). The findings also show that conventional buildings contain nonnegligible amounts of timber, mainly in the form of wooden attics and roofs, which is why they play a relevant role in storing biogenic carbon. In addition to the biogenic $\mathrm{CO}_{2}$ emissions, fossil GHG emissions occur during the production phase of the building products (power supply, transportation to the manufacturing site, etc.). Looking at module $\mathrm{C}$ in Fig 3, it becomes obvious that the biogenic carbon again leaves the product system in the EOL phase in the form of $\mathrm{CO}_{2}$. It is the same amount as module $\mathrm{A}$ introduced, but with a positive sign. In line with EN 16485, the biogenic carbon balance thus results in a zero-sum game over a building's entire life cycle (EN 16485 2014).

Summarizing modules A, B, and C, the results over the whole life cycle for the GWP indicator make up nearly half of the magnitude for the timber constructions as they have been assessed for conventional buildings. Other exemplary building calculations for a SFH and MSRB are shown in Hafner and Schäfer (2017).

In contrast to the small residential timber buildings, the construction of multiresidential timber buildings (Fig 4) make a smaller overall contribution to the reduction of GHG emissions due to higher fire protection requirements. This results in higher mineral material use in primarily wooden constructions.

Looking at module $\mathrm{D}$, we can see that all the analyzed buildings in this study have negative GHG emissions, which means that benefits beyond the system boundary can be achieved with timber and mineral building constructions. The benefits of the timber buildings are higher than those for conventional buildings because of the masses of wood which are thermally recovered and can replace fossil energy. For residential buildings, it can be said that the more the wood used in the construction, the higher the predicted benefits in module $\mathrm{D}$.

For timber buildings, the results of comparing timber-frame and CLT constructions illustrate that a building's temporary carbon storage is of course higher, the more solid wood material (mainly through CLT) is included.

Figure 5 shows the indicator GWP for 10 SFHs (seven timber, three mineral). All timber buildings constructed in CLT result in substantially higher carbon storage per $\mathrm{m}^{2} / \mathrm{GEA}$ (visualized by biogenic GWP in module $A$ ) than is the case for timber-frame buildings. Over the whole lifecycle, however, the results for both constructions (CLT and timber-frame construction) are similar. Only the benefits after EOL (in module D) are higher for CLT construction. The results of all timber construction show higher carbon storage and lower GHG emissions than those for conventional buildings. Nonetheless, the choice of timber in the construction from the environmental point of view should not only be predicated on the amount of stored biogenic carbon but also always on the achieved material efficiency with respect to the relevant function. Hafner and Schäfer 


\section{GWP (fossil and biogenic), for one single family building building (1.1)}

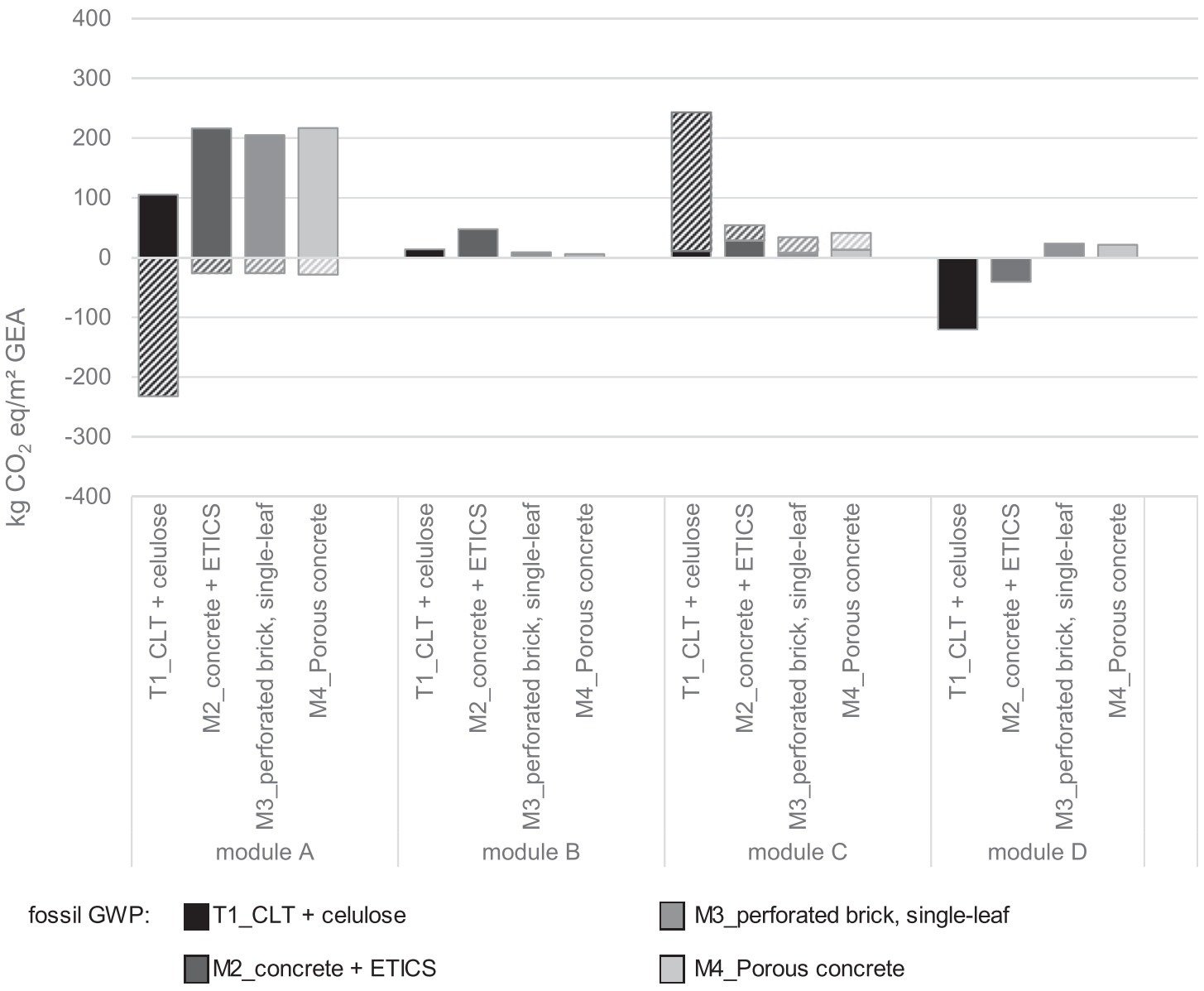

biogenic GWP: share of biogenic GWP in construction material

Life cycle phases

Figure 3. LCA results (indicator GWP) for one exemplary building (single-family house) divided into different life cycle stages A, B, C, and D. Fossil GWP is completely colored and biogenic GWP is shaded (Hafner et al 2017).

(2018) highlight the interdependencies of biogenic carbon storage capacity and material efficiency in timber buildings. In most cases, these aspects appear to be even contradictory in regard to their environmental impact. Because of a rising competition for material, both the criteria "material efficiency" in timber products and "biogenic carbon storage capacity" should always be considered in the decision-making processes. Results show that there is no "best" timber construction that fulfills all the requirements, as each building and with each specific construction needs to fulfill different requirements under varying circumstances.

Based on these calculations, substitution factors on the building level can be derived when replacing a mineral construction with a timber building. The LCA results and the calculated substitution factors can be considered as representative values. 
GWP (fossil and biogenic),

for one multi story building (2.10)

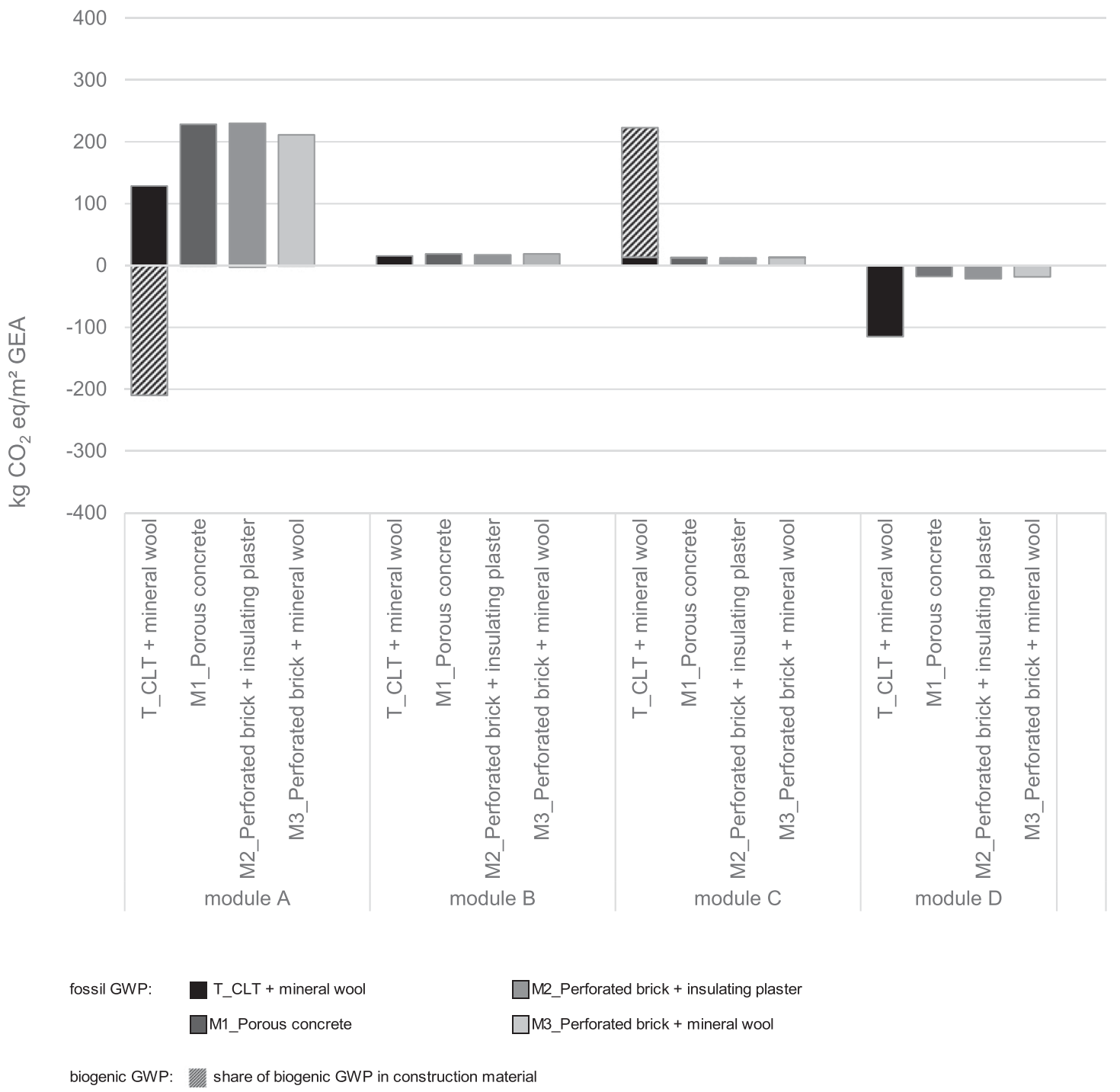

\section{life cycle phases}

Figure 4. LCA results (indicator GWP) for one multistory residential building divided into different life cycle stages A, B, C, and D. GWP is completely colored and biogenic GWP is shaded (Hafner et al 2017).

\section{Substitution on a Building Level}

The results show that all analyzed buildings achieve positive substitution factors for their construction on basis of the current LCA standards (EN 15978 2012; 15804 2014) (see Figs
3-5). The construction elements of the analyzed buildings are the foundation, external walls, internal walls, ceiling, roof, and balcony when present. The relevant building type-timber or mineral-is defined by the load-bearing structure. Further elements included in the buildings as finishing 


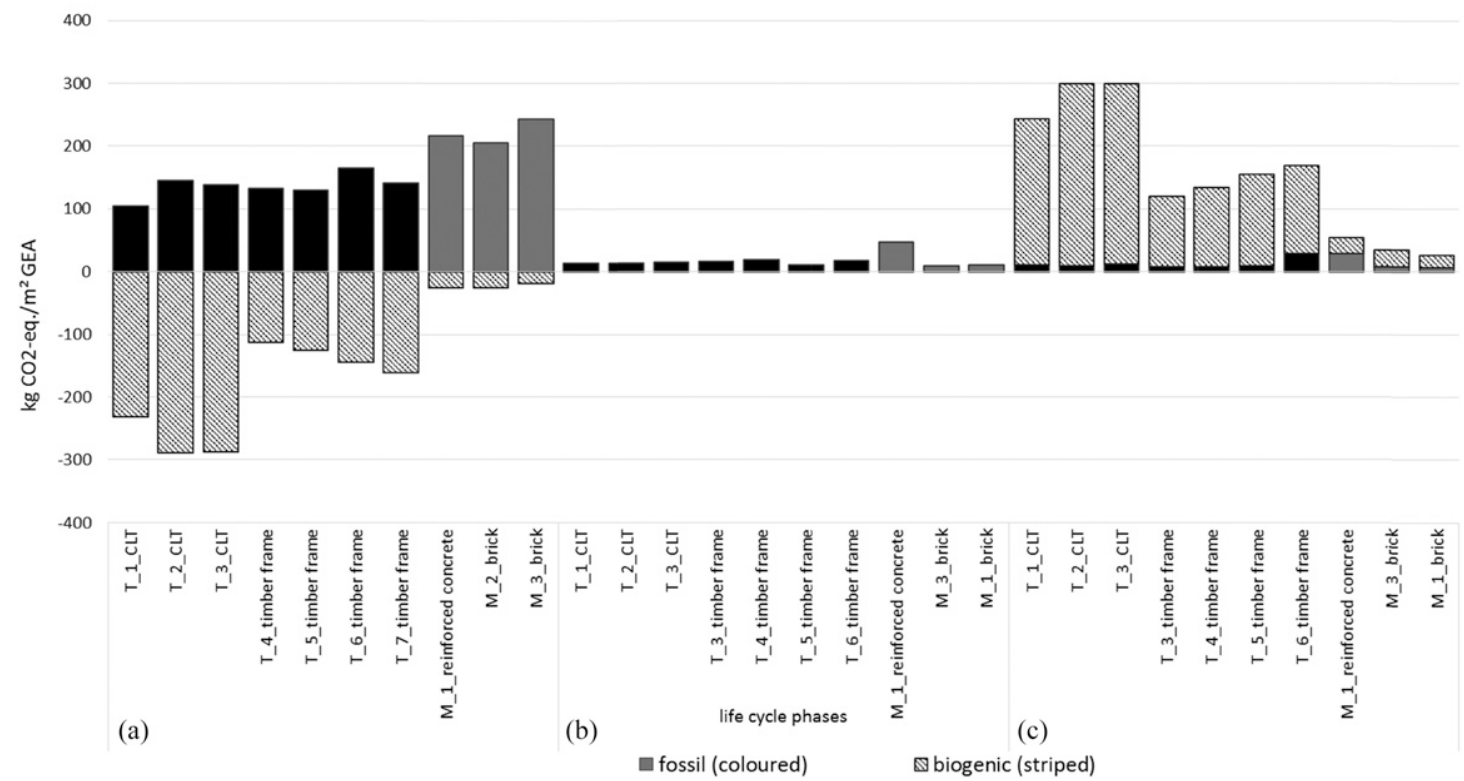

Figure 5. Comparison of fossil GWP and carbon storage for various timber and mineral single-family buildings. T1 to T3 are CLT constructions, and T4 to T7 are timber-frame constructions.

components comprise doors, windows, stairs, flooring, roofing, façade, and technical building equipment. These building elements are included in the assessment but have not been replaced by their relevant nonwood substitutes for the conventional buildings in this basic study because they are independent of the building's type of construction. Furthermore, there are no reliable data available about the representative market situation of finishing products so far. Further research is thus required on this issue. It can be assumed that the inclusion of the finishing components would generate additional substitution effects for all buildings (cf. inter alia Albrecht et al 2008).

The identified substitution factors for the construction of small residential buildings range between 0.35 and 0.56 and between 0.09 and 0.48 for multistory buildings (cf. Hafner et al 2017). This means that small residential buildings can potentially avoid between $35 \%$ and $56 \%$ of released GHG emissions when constructed in timber instead of mineral-based materials. The GHG reduction potential of the analyzed multistory buildings ranges between $9 \%$ and $48 \%$. The magnitude of the substitution factors therefor depend on the used building materials, the individual building design, and the floor plan and height of the building. The more floors a building has, the stricter the fire protection requirements are.

In general, the substitution factors are higher for SFHs/two-family houses than for MSRBs because the requirements for fire safety and sound insulation are not as strict. For example, insulation from renewable material is not allowed in multistory buildings in Germany because of building regulations.

\section{GHG Impacts of Wood Use in Building Sector on a National Level}

On the national level, both scenarios "REF" and "55/15" were calculated including the overall released GHG emissions associated with the different types of buildings along their assumed life cycle of $50 \mathrm{yr}$ and the biogenic carbon storage effects associated with the consumption of wooden building products and their potential 
demand for timber feedstock. The environmental impact associated with the maintenance of relevant building products and elements in the annually erected buildings illustrated in Module B was equally divided over the assumed building's life cycle. In consequence, effects within the projection period up to 2030 and subsequent effects up to the year 2080 following the choice of the building materials could be assessed.

As a first result, the deviation of the future $\mathrm{CO}_{2}$ emissions and removals due to the biogenic carbon storage effect for both scenarios was estimated. In the case of the suggested increase of the share of wooden residential buildings, the average sink effect of $-0.96 \mathrm{Mt} \mathrm{CO}_{2} /$ year in the "REF" scenario could be enhanced by an additional $-0.65 \mathrm{Mt} \mathrm{CO}_{2}$ /year within the totally consumed wood products pool (Fig 6). Because of the assumption of a steadily increasing share of wooden buildings in the market segments for SFH and MSRB in the selected scenario " "55/15," starting from the status quo, the effect also steadily grows over the projected period.

Second, the projected GHG emissions associated with the different building types and their included building products over their entire life cycle were analyzed. For this effect, the biogenic
$\mathrm{CO}_{2}$ emissions were not included to avoid double-counting. For the selected base period, 2011 to 2015, which was applied for projecting the future share of the different building types, about 9.5 $\mathrm{Mt} \mathrm{CO}_{2} \mathrm{e} /$ year were calculated as historic average (compare Fig 7). In the case of the "REF" scenario, this emission budget would first increase to $14.1 \mathrm{Mt} \mathrm{CO}_{2} \mathrm{e}$ in 2016 and subsequently decline to about $8.2 \mathrm{Mt} \mathrm{CO}_{2} \mathrm{e}$ in 2030 because of the forecasted demand for residential buildings (BBSR 2015). Over the projection period 2016-2030, GHG emissions of about 11.3 $\mathrm{Mt} \mathrm{CO}_{2} \mathrm{e}$ on annual average would be emitted, if the housing market forecast were realized while maintaining the current share of both wooden and conventional building types (ie "REF" scenario).

In the case that the wooden market share increases as suggested in the " $55 / 15$ " scenario, the projected annual average GHG emissions amount only to $10.5 \mathrm{Mt} \mathrm{CO}_{2} \mathrm{e}$, see Fig 7. In fact, the GHG emissions originating from wooden residential buildings would steadily increase. However, the increased emissions would not cancel out the simultaneous decrease of GHG emissions from conventional buildings, resulting in an annual climate positive substitution effect of $0.8 \mathrm{Mt}$ $\mathrm{CO}_{2} \mathrm{e}$ on average. Because of the assumed steady

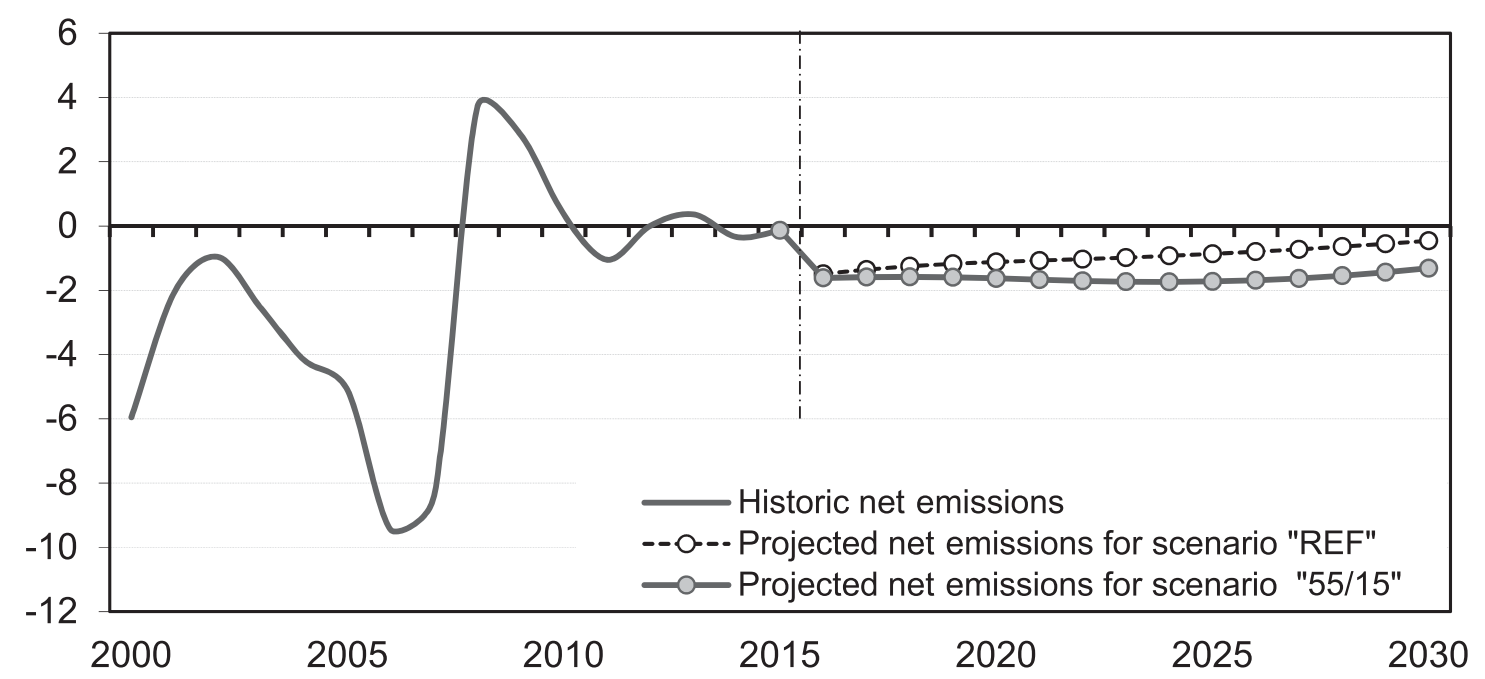

Figure 6. Historic (until 2015) and projected (2016-2030) $\mathrm{CO}_{2}$ emissions and removals associated with biogenic carbon storage effects in wood products for scenarios "REF" and " $55 / 15$ " (in $\mathrm{Mt} \mathrm{CO}_{2}$ ). It shows that when carbon storage effects on the national level are higher (more negative), more wood is used in the buildings. 


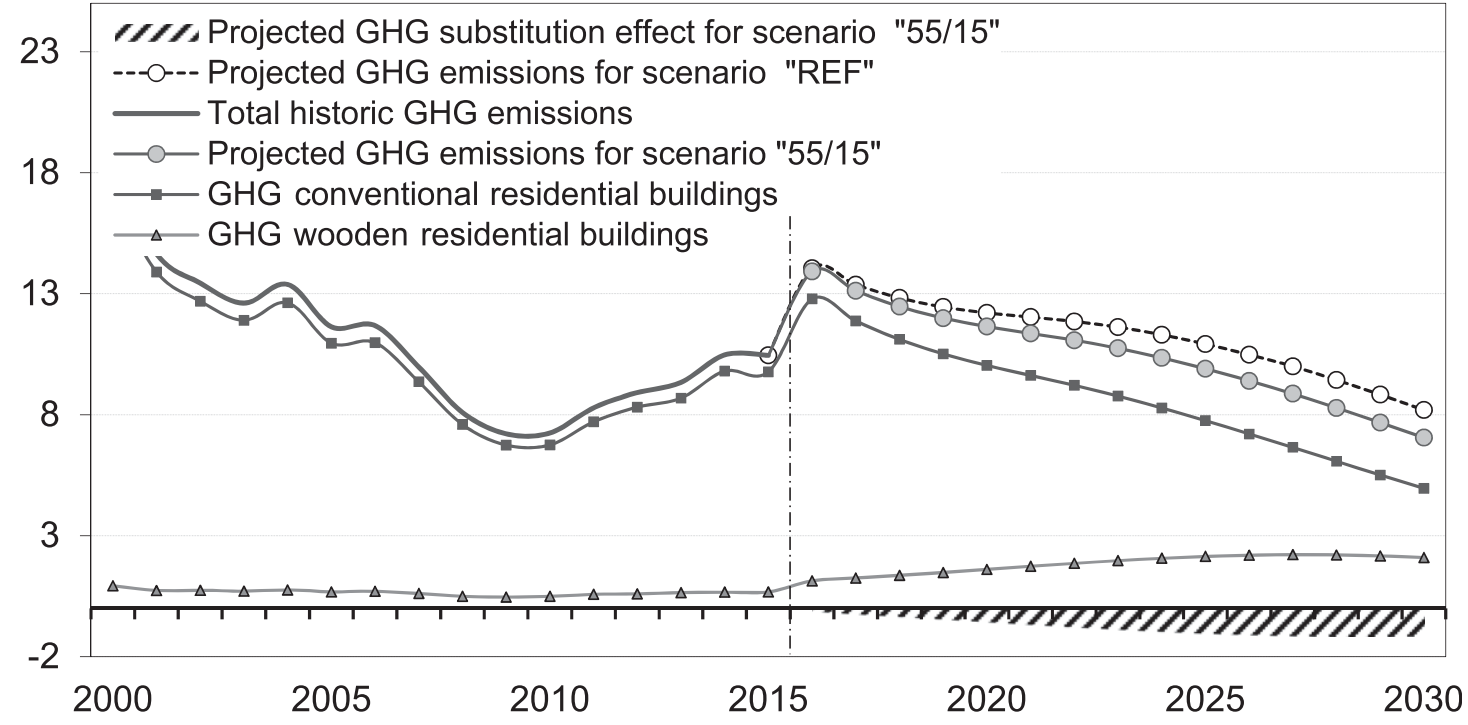

Figure 7. Historic (until 2015) and projected (2016-2030) GHG emissions for scenarios "REF" and "55/15" and associated GHG substitution potential (excluding biogenic $\mathrm{CO}_{2}$ ) (in $\mathrm{Mt}^{-} \mathrm{O}_{2} \mathrm{e}$ ). It shows projections of GHG substitution potential on the national level. The substitution potential rises because of the higher number of timber buildings and less conventional buildings. This results in less GHG emissions for the scenario "55/15" as compared with the scenario "REF."

increase of the market share of wooden houses, starting from the current situation, the substitution effect increases its impact especially at the end of the projection period, with more than 1.1 Mt $\mathrm{CO}_{2} \mathrm{e}$ of GHG emissions that could be mitigated through the increased use of wood in the construction of residential buildings only.

Further $\mathrm{CO}_{2}$ reduction potential could be released if, in addition to construction materials, the finishing elements of the building, such as doors, windows, flooring, and outer cladding, were also accounted for. Because timber-finishing products can be installed in every building, independent of the building's construction, it is particularly important that the potential of the finishing elements not be underestimated. Another advantage is that the potential derived from the finishing elements can also be partly released in existing buildings. To understand the in-depth effects of finishing elements, further study is necessary.

\section{CONCLUSIONS}

The current standards for LCA to be applied for assessing sustainability aspects and environmental impacts in the building sector are sufficiently clear to quantify GHG emissions and to illustrate the biogenic carbon amounts contained in wooden building products on the building level. They are complemented by datasets following these standards (eg ÖKOBAUDAT) and allow for calculating comparable LCAs for buildings. In addition, such standard-compliant LCA datasets for wooden building products can be consistently combined with national statistics which form the basis for estimating the annual $\mathrm{CO}_{2}$ emissions and removals associated with the biogenic carbon storage effects in line with the methodological requirements of IPCC. As time series on the annual production and trade of semifinished wood products follow the internationally agreed classification system of FAO (cf. FAO 2018), the combination of such consistent and standard-compliant LCA data should be possible for all relevant countries. Further analysis of potential implications on changing consumption patterns of wood as building material, however, requires the design of a plausible reference scenario and further information or statistics on the different types of erected buildings according to the mainly used material components within those building classes. 
In comparison with conventional products, the use of wood products in the building sector shows clear environmental advantages such as a lower GWP over the building's life cycle and their contribution to the $\mathrm{CO}_{2}$ emissions and removals of the land-use sector because of their temporary storage of biogenic carbon. The previously described methods are used to calculate these changes in the carbon stock in the wood products pool on the national level and form a basis to relate the potential GHG implications associated with the use of wood as building material to the national GHG inventories.

The explained method shows a consistent approach which allows providing fact-based evidence that the use of wood in buildings can contribute to reaching climate protection targets.

\section{REFERENCES}

Albrecht S, Rüter S, Welling J, Knauf M, Mantau U, Braune A, Baitz M, Weimar H, Sörgel C, Kreißig J, Deimling S, Hellwig S (2008) Ökologische Potenziale durch Holznutzung gezielt fördern. Report of the Institute of Wood Technology and Wood Biology, No. 2008/5. Johann Heinrich von Thünen Institute (vTI), Hamburg, Germany. 298 pp.

BBSR (2015) Federal Institute for Research on Building, Urban Affairs and Spatial Development: Oekobau.dat database. http://www.oekobaudat.de (Version 2015).

BBSR (2016) Federal Institute for Research on Building, Urban Affairs and Spatial Development: BNB "Bewertungssystem Nachhaltiges Bauen" (Assessment System for Sustainable Building). Federal Institute for Research on Building, Urban Affairs and Spatial Development, Berlin, Germany.

BMI (2018) Federal Ministry of the Interior, Building and Community (BMI): ÖKOBAUDAT_-Sustainable Construction Information Portal. http://www.oekobaudat.de/ en.

BMUB (2011) Federal Ministry for the Environment, Nature Conservation, Construction and Nuclear Safety (BMUB) 2011: Nutzungsdauern von Bauteilen zur Lebenszyklusanalyse nach BNB. [Useful Lives of Construction Parts for LCA calculations].

Brockmann T (2017) German ÖKOBAUDAT goes international: An online infrastructure for LCA as Basis for International Structure. Conference Proc Word Sustainable Built Environment Conference, Hong Kong, 2017. ISBN 978-988-77943-0-1.

Diederichs S (2014a) Status quo for life cycle inventory and environmental impact assessment of the core sawmill products in Germany. Wood Fiber Sci 46(1):65-84.
Diederichs S (2014b) Status quo for life cycle inventory and environmental impact assessment of wood-based panel products in Germany. Wood Fiber Sci 46(3):340-355.

EN 15643 (2010) Part 1: Sustainability of construction works. Sustainability of buildings. General Framework. European Committee for Standardization.

EN 15978 (2012) Sustainability of construction works Assessment of environmental performance of buildings - Calculation method. European Committee for Standardization.

EN 16485 (2014) Round and sawn timber - Environmental Product Declarations - Product category rules for wood and wood-based products for use in construction. European Committee for Standardization.

EN 15804 (2014) Sustainability of construction works Environmental product declarations - Core rules for the product category of construction products. European Committee for Standardization.

EnEV (2009) Energieeinsparverordnung für Gebäude 2009. http:// www.enev-online.org/enev_2009_volltext/ (10 April 2017).

European Commission (EC) (2010) Directive 2010/31/EU of the European Parliament and the Council on the energy performance of buildings (26 April 2018).

European Commission (EC) (2014) Communication from the commission to the European parliament, the council, the European economic and social committee of the regions. Resource efficiency opportunities in the building sector. http:// eur-lex.europa.eu/legal-content/EN/TXT/PDF/?uri=CELEX: 52014DC0445\&from=EN (28 June 2017).

FAO (2018) Classification and definitions of forest products 1982. http://www.fao.org/forestry/statistics/80572/en / (23 May 2018).

FNR Fachagentur Nachwachsende Rohstoffe e V. [Agency for Renewable Resources] (2017) Collaborative project 'Data base for assessing a sustainable and efficient use of wood in the German construction sector' (HolzImBauDat). https://www.fnr.de/index.php?id $=11150 \& f k z=22016216 /$ (23 September 2017).

Hafner A (2017) How building with wood can be linked to sales of building plots: Results from an exemplary site development in Munich, Germany. Sustainability 9(6): 947.

Hafner A, Schäfer S (2017) Comparative LCA study of different timber and mineral buildings and calculation method for substitution factors on building level. J Clean Prod 167:630-642. doi: 10.1016/j.jclepro.2017.08.203.

Hafner A, Schäfer S (2018) Environmental aspects of material efficiency versus carbon storage in timber buildings. Eur J Wood Wood Prod 76(3):1045-1059.

Hafner A, et al (ed) (2017) Treibhausgasbilanzierung von Holzgebäuden - Umsetzung neuer Anforderungen an Ökobilanzen und Ermittlung empirischer Substitutionsfaktoren (THG-Holzbau) [Greenhouse gas balances for timber buildings - Implementation of new requirements for lifecycle assessments and calculation of empiric substitution factors]. Bochum. Projektbericht Waldklimafonds 28W-B3-054-01. BMEL/BMUB. ISBN: 978-3-00-055101-7. 
Heuer E, Baldauf T, Schmitz F, Rüter S (2016) Was tragen Wald und Holz zum Klimaschutz in Deutschland bei? AFZ Der Wald 115/2016. [What do forest and wood contribute to climate protection in Germany?].

ISO/TS 14071 (2014) Environmental management - Life cycle assessment - Critical review processes and reviewer competencies: Additional requirements and guidelines to ISO 14044:2006.

ISO 21930 (2017) Sustainability in buildings and civil engineering works - Core rules for environmental product declarations of construction products and services. International Organization for Standardization.

Rüter S (2012) Umwelt-Produktdeklarationen für Bauprodukte nach EN 15804. Holztechnologie 53(4):56-57. [Environmental Product Declarations of Building Products according to EN 15804].

Rüter S (2013) Der Umweltbeitrag der Holznutzung. Pages 86-97 in P Cheret, K Schwaner, and A Seidel, eds. Urbaner Holzbau-Chancen und Potenziale für die Stadt. DOM Publishers, Berlin, Germany. [The Environmental Contribution of Wood Utilization].

Rüter S (2016) Harvested Wood Products (4.G). Pages 615-618 in $\mathrm{P}$ Gniffke, ed. Submission under the United Nations Framework Convention on Climate Change 2015-National Inventory Report for the German Greenhouse Gas Inventory 1990-2013. Federal Environment Agency, Climate Change 03/2016, Dessau, Germany (January 2016).

Rüter S (2017) Der Beitrag der stofflichen Nutzung von Holz zum Klimaschutz-Das Modell WoodCarbonMonitor. Technische Universität München, Wissenschaftszentrum Weihenstephan für Ernährung, Landnutzung und Umwelt, doctoral thesis. $270 \mathrm{pp}$. [The Contribution of the Material Wood Use to Climate Protection - the WoodCarbonMonitor Model].
Rüter S, Alfredsen G, de Aquino Ximenes F, Guendehou S, Pingoud K, Tsunetsugu Y, McCusker A (2014) Harvested Wood Products (Section 2.8). Pages 109-134 in T Hiraishi, T Krug, K Tanabe, N Srivastava, B Jamsranjav, M Fukuda, and GT Troxler, eds. 2013 Revised Supplementary Methods and Good Practice Guidance Arising from the Kyoto Protocol. Published: IPCC, Switzerland.

Rüter S, Diederichs S (2012) Ökobilanz-Basisdaten für Bauprodukte aus Holz. Report No 2012/01, ThünenInstitute of Wood Research. 316 pp.

Rüter S, Diederichs S (2017) Abschätzung der Auswirkungen eines verstärkten Holzeinsatzes im Bausektor auf die nationale Treibhausgasbilanz. Pages 65-79 in Hafner et al, ed. Treibhausgasbilanzierung von Holzgebäuden Umsetzung neuer Anforderungen an Ökobilanzen und Ermittlung empirischer Substitutionsfaktoren (THGHolzbau) Bochum. Projektbericht Waldklimafonds 28WB-3-054-01. BMEL/BMUB. ISBN: 978-3-00-055101-7.

Sathre R, O'Connor J (2010) A Synthesis of Research on Wood Products \& Greenhouse Gas Impacts. 117 pp. 2nd Edition. Technical Report No. TR-19R, FP Innovations.

Umweltbundesamt (2017) United Nations Framework Convention on Climate Change and the Kyoto Protocol 2016 - National Inventory Report for the German Greenhouse Gas Inventory 1990-2015. Pages 1091 in $\mathrm{P}$ Gniffke, ed. Umweltbundesamt, Climate Change.

UNFCCC (2012) Report of the CMP on its seventh session, held in Durban from 28 November to 11 December 2011, Addendum: Decision 2/CMP.7 on Land use, land-use change and forestry. FCCC/KP/CMP/2011/10/Add.1.

UNFCCC (2017) United Nations Framework Convention of Climate Change Meetings - Paris Climate Change Conference November 2015 [online]. http://unfccc.int/meetings/ paris_nov_2015/meeting/8926.php (17 March 2017). 